Quim. Nova, Vol. 35, No. 2, 420-429, 2012

\title{
INVESTIGANDO A PRESENÇA DA HISTÓRIA DA CIÊNCIA EM LIVROS DIDÁTICOS DE QUÍMICA GERAL PARA O ENSINO SUPERIOR
}

\author{
Maria Angélica Moreira Fernandes e Paulo Alves Porto* \\ Instituto de Química, Universidade de São Paulo, Av. Prof. Lineu Prestes, 748 05508-900 São Paulo - SP, Brasil
}

Recebido em 7/4/11; aceito em 25/7/11; publicado na web em 26/9/11

\begin{abstract}
INVESTIGATING THE PRESENCE OF THE HISTORY OF SCIENCE IN UNIVERSITY GENERAL CHEMISTRY TEXTBOOKS. This paper aims at analyzing the history of science content of three general chemistry textbooks used in Brazilian universities: the translations of Kotz and Treichel's Chemistry \& Chemical Reactivity, Atkins and Jones's Chemical Principles, and Garritz and Chamizo's Química. Results revealed different trends for the inclusion of history of science in chemistry teaching. Kotz \& Treichel and Atkins \& Jones used history mainly as curiosity and ornament. Garritz \& Chamizo adopted the historical approach as one of the organizing axis of their textbook. Nevertheless, the historical content of the three textbooks may be criticized from current historiographical standpoint.
\end{abstract}

Keywords: general chemistry; textbooks; history of chemistry.

\section{INTRODUÇÃO}

Os livros didáticos são importantes ferramentas no processo educacional, sendo, por vezes, considerados o principal eixo para a condução desse processo, influenciando tanto os enfoques adotados pelos professores quanto as estratégias de aprendizagem dos alunos. ${ }^{1}$ Cada livro didático traz consigo, explícita ou implicitamente, concepções a respeito da natureza da ciência e do conhecimento científico. Tais concepções são relevantes para o ensino de ciências e constituem, por exemplo, um dos critérios para avaliação dos livros didáticos no âmbito do Programa Nacional do Livro Didático para o Ensino Médio (PNLEM 2007) - o qual menciona a "natureza e construção da ciência" e o "tratamento dos conteúdos científicos". Considere-se, a título de ilustração, a concepção de uma "descoberta científica". Em muitos livros didáticos, a descoberta é mostrada como um evento instantâneo e atribuída a um único cientista. De acordo com a contemporânea filosofia da ciência, porém, uma descoberta é mais bem caracterizada como um processo que pode se prolongar no tempo e que se desenvolve no âmbito de uma comunidade científica. Conforme discutiu Thomas Kuhn, a descoberta do oxigênio constitui-se em um bom exemplo: não se tratava apenas de isolar uma nova substância, mas de compreender sua relação com as demais em um determinado contexto teórico. ${ }^{2}$ Ampliando essa discussão para a formação de profissionais de Química, também é importante que se analise como o conhecimento científico é apresentado no ensino superior. Nesse âmbito, os livros didáticos têm a função de promover uma visão organizada do conhecimento científico compartilhado por uma determinada comunidade, resumindo o consenso disciplinar dessa área. Ao destacar a importância dos livros didáticos na formação em Ciências da Natureza, Kuhn já observara que o estudo dos clássicos da história da ciência não é encorajado nesse processo, destinado a imergir o estudante na matriz disciplinar contemporânea. ${ }^{3}$ Escrevendo sobre os livros didáticos, Kuhn afirmou:

É característica dos manuais ${ }^{4}$ científicos conterem apenas um pouco de história, seja um capítulo introdutório, seja, como acontece mais frequentemente, em referências dispersas aos grandes heróis de uma época anterior. Através dessas refe-

*e-mail: palporto@iq.usp.br rências, tanto os estudantes como os profissionais sentem-se participando de uma longa tradição histórica. Contudo, a tradição derivada dos manuais, da qual os cientistas se sentem participantes, jamais existiu. (...) [Os livros didáticos] referem-se somente àquelas partes do trabalho de antigos cientistas que podem facilmente ser consideradas como contribuições ao enunciado e à solução dos problemas apresentados pelo paradigma dos manuais (p. 175). ${ }^{2}$

Desse modo, a história da ciência aparece nos livros didáticos com uma função persuasiva, de reafirmar a estrutura da ciência atual. ${ }^{2}$ Embora essa estratégia didática seja compreensível e venha obtendo sucesso no alcance dos objetivos a que se propõe, não deixa de ser paradoxal que, para ensinar ciência, seja omitida a análise de uma de suas características essenciais, que é o modo como ela é produzida. Em tempos mais recentes, outras funções foram propostas para a história da ciência no ensino. ${ }^{5}$ Nem sempre, porém, o conteúdo de história da ciência encontrado em livros didáticos está de acordo com o que se preconiza para o ensino de ciências na atualidade. ${ }^{6}$ Martins $^{7}$ adverte para a série de informações inadvertidamente errôneas sobre a história da ciência que podem ser encontradas em livros didáticos e que podem contribuir para a construção de visões inadequadas não apenas da história da ciência, mas da própria ciência.

Nesse contexto, este trabalho buscou investigar a forma como a história da ciência está sendo apresentada em livros didáticos de química geral, voltados para disciplinas introdutórias do nível superior. Entendemos que os conteúdos de história da ciência que constam nesses livros podem contribuir para a construção de concepções a respeito da natureza da ciência por parte dos estudantes. O interesse se justifica também pelo ainda pequeno número de estudos analisando livros didáticos de química de nível superior. Para a análise desenvolvida aqui, partimos do instrumento desenvolvido por Leite, ${ }^{8}$ ao qual incorporamos algumas modificações, como será explicado a seguir.

\section{METODOLOGIA}

Este trabalho investiga a inserção de conteúdos de história da ciência em livros didáticos de Química utilizados no ensino superior. Para a escolha dos títulos a analisar, foi feito um breve levantamento via internet, nos sítios de disciplinas de química geral de cursos de 
graduação em Química de Universidades brasileiras (USP, UFMG, UFSC, UnB, Mackenzie [São Paulo, SP]). Tal levantamento não teve a pretensão de ser completo ou abrangente: apenas teve a finalidade de balizar a escolha de livros que estejam efetivamente difundidos no contexto do ensino de química geral. Dentre os vários livros sugeridos nas bibliografias das disciplinas, foram selecionados dois, que têm sido largamente utilizados em cursos introdutórios de química: Química Geral e Reações Químicas, de Kotz e Treichel; ${ }^{9}$ e Princípios de Química, de Atkins e Jones..$^{10}$ Além desses, foi investigado também o livro Química, de Garritz e Chamizo ${ }^{11}$ que, embora não seja tão indicado em disciplinas introdutórias de ensino superior quanto os dois livros anteriores, foi escolhido porque seus autores demonstraram a preocupação de inserir conteúdos de história da ciência no desenvolvimento dos temas em estudo sendo, portanto, um material interessante para a reflexão a respeito das possibilidades de aproximação da história da ciência ao ensino de química. Para que houvesse maior uniformidade na comparação entre os livros, procurou-se abranger uma extensão de capítulos que cobrisse, aproximadamente, os mesmos conteúdos nos três. Assim, tomouse apenas o volume 1 do livro de Kotz e Treichel, que consta de 2 volumes. O livro de Atkins e Jones, por sua vez, apresenta em seu início uma grande seção introdutória com fundamentos de química geral, seguida por capítulos numerados. Deste livro foram analisados da Introdução até o capítulo 8 (inclusive). O volume único do livro de Garritz e Chamizo foi analisado em sua totalidade.

Para proceder a essa investigação, partiu-se do instrumento de análise proposto por Leite,${ }^{8} \mathrm{o}$ qual foi desenvolvido para o levantamento de dados quantitativos relevantes a respeito dos conteúdos históricos em livros didáticos de ciências. Assim, pode-se não apenas mapear os tipos de abordagem mais utilizados, mas também observar como se dá a inserção dos conteúdos, fornecendo subsídios para posteriores reflexões e discussões. Algumas alterações foram inseridas no instrumento original, em função das observações que foram sendo feitas no decorrer da pesquisa, visando esclarecer melhor alguns dos critérios utilizados e também adaptar as características do instrumento às peculiaridades da pesquisa.

O instrumento proposto por Leite está estruturado na forma de tabelas, que organizam diversas categorias de análise. Essas tabelas do instrumento constituem, na expressão utilizada pela autora, "dimensões" de análise. Essas grandes dimensões são 8, a saber: tipo e organização da informação histórica; materiais utilizados para apresentar a informação histórica; contextos aos quais a informação histórica é relacionada; estatuto do conteúdo histórico; atividades de aprendizagem que abrangem a história da ciência; consistência interna do livro (no que se refere à informação histórica); bibliografia em história da ciência e, exatidão e precisão da informação histórica.

Nas três primeiras dimensões, o foco de análise é a informação inserida no texto: como ela aparece, quais são os aspectos abordados, etc. A primeira dimensão de análise se refere a "Tipo e organização da informação histórica", e se divide em subdimensões: a primeira diz respeito à dimensão humana dos personagens que fazem a ciência ("Personagens"); a segunda se refere ao processo de transformação da ciência ao longo do tempo ("Evolução da ciência"). Cada uma delas, por sua vez, se divide em categorias. Conforme esclarece Leite, essas categorias foram propostas a partir de fontes em história da ciência, estudo de concepções a respeito da história da ciência e de estudos anteriores sobre como a história da ciência costuma aparecer em livros didáticos.

No que diz respeito à "Evolução da ciência", tenta-se caracterizar como é descrito o processo de transformação das ideias científicas ("Tipo de evolução") e, também, a quem se atribui a responsabilidade por protagonizar esse processo ("Responsável"). Assim, na subdivisão "Tipo de evolução" aparecem cinco categorias. Na primeira, "Men- ção", a abordagem é superficial, não havendo discussão da descoberta ou ideia científica. Na segunda, caracteriza-se que o livro se limita a uma "Descrição" da descoberta ou ideia, sem relacioná-la a outras ideias em uma perspectiva de transformação histórica. Quando ideias que se sucederam historicamente são mencionadas ou descritas em um mesmo trecho, mas nenhuma relação entre elas é explicitada, caracteriza-se a categoria "Períodos discretos". Se a sucessão de ideias sugere apenas que uma levou à outra, tem-se a "Evolução linear". Finalmente, se a transformação das ideias for associada a debates, contradições e controvérsias, considerou-se como uma ocorrência de "Evolução real".

Na subdivisão "Responsável", as mudanças nas ideias científicas são categorizadas conforme são atribuídas a indivíduos isoladamente, a dois ou mais cientistas trabalhando em conjunto e citados nominalmente, ou ainda a uma comunidade científica (neste caso, quando o texto não indica nomes, mas apenas atribuições genéricas como "os cientistas descobriram", "os químicos sabiam", etc.).

Na segunda dimensão de análise, temos os materiais utilizados no livro para apresentar o conteúdo de história da ciência. As categorias consideradas foram: imagens de cientistas; imagens de equipamentos, máquinas, etc.; textos originais (fontes primárias); textos escritos pelo próprio autor do livro didático; fontes secundárias produzidas por outros autores; experimentos históricos; outros.

A terceira dimensão se refere à contextualização das ocorrências em história da ciência, isto é, se o conteúdo histórico estava inserido em algum dos seguintes contextos: científico; tecnológico; social; político e (ou) religioso. Essa dimensão do instrumento original mereceu um novo ângulo de observação: o instrumento proposto por Leite sugere a contagem dos contextos a que o autor se refere nas ocorrências históricas. Porém, se um mesmo episódio estiver relacionado a mais de um contexto, isso poderá dar a impressão de que há mais ocorrências contextualizadas do que de fato há. Assim, procedemos também à contagem do número total de ocorrências que foram apresentadas de maneira contextualizada, de modo a ter mais uma informação relevante a esse respeito.

A quarta dimensão de análise diz respeito ao estatuto da informação histórica contida no texto. Assim, se procurou observar se as referências à história da ciência integravam o corpo principal do texto, ou se ocorriam em seções ou atividades consideradas complementares - sendo, assim, categorizadas como fundamentais ou complementares.

A quinta dimensão avalia atividades de aprendizagem (exercícios, por exemplo) que incluem alguma referência à história da ciência. A simples leitura de um texto de caráter histórico não foi considerada aqui como uma atividade: era preciso que algum outro tipo de engajamento do aluno estivesse envolvido, para que a ocorrência fosse computada nesta dimensão - a qual se divide em duas subdimensões. No que se refere ao "Estatuto da Atividade", estas foram classificadas em compulsórias ou livres. Quanto ao "Tipo de Atividade", as categorias são: guia de leitura; pesquisa bibliográfica; análise de informação histórica; experimentos históricos; outras atividades.

A sexta dimensão, intitulada "Consistência interna do livro", refere-se à maneira como as ocorrências em história da ciência se encontram distribuídas: se concentradas em apenas um ou poucos capítulos, se na maioria dos capítulos, ou se presentes ao longo de todo o texto.

Na sétima dimensão, referente à bibliografia, foram categorizados os diferentes tipos de livros indicados como referências, considerados como: livros de história da ciência; livros de ciência que abordam a história da ciência; ou livros de áreas afins (por exemplo: história geral, filosofia ou sociologia da ciência e divulgação da ciência).

Finalmente, a oitava e última dimensão, "Exatidão e precisão da informação histórica", não se traduz na construção de tabelas, 
mas requer a análise qualitativa das ocorrências - sendo que, neste trabalho, se adotou como referencial para essa análise a nova historiografia da ciência. ${ }^{12}$

Além disso, para complementar essa análise qualitativa, procuramos analisar as ocorrências classificadas nas categorias "Descrição", "Períodos discretos", "Evolução linear" e "Evolução real" utilizando outros critérios, não presentes no instrumento proposto por Leite. A classificação de acordo com essas categorias complementares foi limitada apenas a essas ocorrências, pelo fato de que representam ocorrências mais elaboradas do que a simples "Menção" a uma ideia ou descoberta científica.

Em uma das categorias complementares, intitulada "Teoria $\mathrm{x}$ prática”, se procurou analisar se o autor do livro relaciona o episódio científico com algum aspecto prático (seja como origem, ou como consequência da ideia ou descoberta), ou se apresenta o evento científico apenas sob o ponto de vista das teorias científicas por si mesmas. Nas outras categorias, se procurou identificar quais períodos históricos são predominantes nas ocorrências observadas, bem como a localização geográfica dos eventos (local de nascimento de cientistas, localização de laboratórios, etc.) citados nos livros.

\section{RESULTADOS E DISCUSSÃO}

\section{Dimensão 1 - Tipo e organização da informação histórica}

Ao fazermos a análise dos livros, foram feitas algumas alterações no instrumento proposto por Leite, de modo a possibilitar um levantamento mais detalhado e informativo a respeito do perfil da informação analisada. Em nossa primeira dimensão de análise, "Tipo e organização da informação histórica", a subdivisão "Caracterização" do cientista inclui uma categoria não existente no instrumento original: "Sem atribuição". Observou-se que grande parte das ocorrências de caracterização dos cientistas, ao contrário do que sugeria o instrumento de Leite, aparece sem caracterizar o cientista como gênio ou como uma pessoa comum. Entendeu-se que não atribuir características ao cientista não é o mesmo que caracterizá-lo como uma pessoa comum, daí a necessidade de se criar a nova categoria.

A Tabela 1 mostra os números totais de ocorrências dessas categorias, para cada um dos três livros investigados.

Tabela 1. Tipo e organização da informação histórica - Personagens

\begin{tabular}{lccc}
\hline $\begin{array}{l}\text { Categorias } \\
\text { Personagens (pensadores, } \\
\text { filósofos, cientistas) }\end{array}$ & $\begin{array}{c}\text { Kotz e } \\
\text { Treichel }\end{array}$ & $\begin{array}{c}\text { Atkins e } \\
\text { Jones }\end{array}$ & $\begin{array}{c}\text { Garritz e } \\
\text { Chamizo }\end{array}$ \\
\hline Vida dos personagens & & & \\
\hline Informações biográficas & 52 & 46 & 110 \\
Características pessoais & - & - & 7 \\
Curiosidades & 4 & 5 & 21 \\
\hline Caracterização & & & \\
\hline Famoso/Gênio & 3 & 4 & 49 \\
Pessoa comum & 1 & - & 1 \\
Sem atribuição & 73 & 79 & 172 \\
\hline
\end{tabular}

Observa-se um perfil semelhante nos livros de Kotz e Treichel e Atkins e Jones. Em ambos, a tendência é apresentar os cientistas por meio de informações biográficas que não chegam a ser suficientes para delinear sua dimensão humana. Em geral, essas informações se resumem ao nome do cientista, suas datas de nascimento e morte e, com frequência um pouco menor, sua nacionalidade. Quanto à caracterização, observa-se que a categoria "Sem atribuição" predomina e, nas poucas vezes em que alguma característica foi atribuída aos cientistas, foi no sentido de apresentá-lo como "gênio" ou "famoso".
Quanto aos resultados obtidos para o livro de Garritz e Chamizo, primeiramente, chama a atenção a quantidade de ocorrências que aparece. Se nos dois livros analisados anteriormente o número total de ocorrências não chega a uma centena, no livro de Garritz e Chamizo esse número chega a 211 ocorrências. Também se observa maior distribuição das ocorrências entre as diversas categorias consideradas.

Analisando os resultados referentes à "Vida dos personagens", o livro de Garritz e Chamizo seguiu de certa forma a tendência identificada nos outros dois livros, ao dar ênfase para as características biográficas. Por outro lado, este livro inseriu informações a respeito das características pessoais dos cientistas, diferente dos anteriores que não contemplaram essa categoria. Na subdivisão de análise "Caracterização", semelhante aos outros livros, na maioria das vezes os cientistas são apresentados sem caracterização pessoal, nem como "gênios", nem como "pessoas comuns". Entretanto, bem diferente dos livros de Atkins e Jones e Kotz e Treichel, tanto em termos absolutos como relativos, a quantidade de ocorrências em que são apresentadas características de genialidade, fama ou destaque dos cientistas é significativa. Fugindo à tendência de superficialidade dos outros dois livros, Garritz e Chamizo buscam chamar a atenção e atribuir importância também para cientistas latinoamericanos, numa proposta de tentar aproximar os estudantes da ciência que é feita nos países da região. Observa-se que esse recurso tem um significado diferente do que nos outros livros analisados, pois Garritz e Chamizo buscam se utilizar da história da ciência para alcançar maior envolvimento afetivo dos alunos, e não para simplesmente apresentar dados superficiais a respeito de cientistas. Ainda assim, praticamente não se observa a caracterização do cientista como "pessoa comum" - o que pode provocar um efeito oposto ao desejado, isto é, não conseguir com que o estudante se identifique com o cientista.

Tabela 2. Tipo e organização da informação histórica - Evolução da Ciência

\begin{tabular}{lccc}
\hline $\begin{array}{l}\text { Categorias } \\
\text { Evolução da ciência }\end{array}$ & $\begin{array}{c}\text { Kotz e } \\
\text { Treichel }\end{array}$ & $\begin{array}{c}\text { Atkins e } \\
\text { Jones }\end{array}$ & $\begin{array}{c}\text { Garritz e } \\
\text { Chamizo }\end{array}$ \\
\hline Tipo de evolução & 59 & 56 & 104 \\
Simples menção & 9 & 13 & 35 \\
Descrição & 2 & 1 & 6 \\
Períodos discretos & 10 & 15 & 41 \\
Evolução linear & 6 & 3 & 25 \\
Evolução real & & & \\
\hline Responsável & 53 & 66 & 195 \\
\hline Cientista individual & 15 & 7 & 30 \\
Grupo de cientistas & 14 & 24 & 87 \\
Comunidade científica & & &
\end{tabular}

Na dimensão "Evolução da ciência", a categoria "Simples menção" revela superficialidade quanto à informação histórica, enquanto as categorias "Evolução linear" e "Evolução real" pressupõem um pouco mais de aprofundamento, trazendo concepções implícitas a respeito do processo de evolução da ciência. Observa-se, na Tabela 2 , que os dois livros mais recomendados apresentam uma abordagem histórica mais superficial, tanto pela pequena quantidade total de ocorrências, como pelo fato de a maioria das ocorrências serem menções ou descrições. Totalizando as ocorrências, os números são bastante parecidos: 88 no total no livro de Atkins e Jones, e 86 no total para Kotz e Treichel. Em ambos, a grande maioria das ocorrências aparece na forma de "simples menção" a fatos ou descobertas na ciência. Essa categoria nos mostra como a história da ciência aparece 
de maneira pouco aprofundada. Quando aparece com um pouco mais de aprofundamento, conforme nos mostram as categorias seguintes, observamos que a categoria "Evolução linear" aparece de forma predominante, seguida de "Descrição". Mas há uma pequena diferença quanto ao aprofundamento das ocorrências: aparece maior número de ocorrências mais aprofundadas em Atkins e Jones. Entretanto, esse aprofundamento se concentra mais em "Evolução linear", enquanto observamos maior distribuição em Kotz e Treichel. Na subdimensão "Responsável", observamos que as mudanças na ciência, na maior parte das vezes, são atribuídas a cientistas individuais, mais do que a grupos de cientistas ou à comunidade científica como um todo. Em resumo, tem-se uma história da ciência apresentada como um desenvolvimento linear, trabalhada sem muito aprofundamento, onde os cientistas, também apresentados de maneira superficial, através de escassos dados biográficos, trabalhando individualmente, são responsáveis por esse desenvolvimento da ciência. É uma concepção de história da ciência que remete a uma abordagem historiográfica hoje considerada ultrapassada - segundo a qual os cientistas, personagens principais, participam de forma genial de um desenvolvimento linear e progressivo. ${ }^{12}$

Com relação à apresentação da "Evolução da ciência", o livro de Garritz e Chamizo também se diferencia dos demais. De fato, a categoria mais presente é a menção a episódios, o que poderia sugerir uma abordagem mais superficial. Entretanto, as demais categorias ("Descrição", "Períodos discretos", "Evolução linear" e "Evolução real"), que sugerem uma abordagem mais aprofundada, somadas, superam o número de simples menções. Dessa forma, o livro tende a aprofundar o conteúdo histórico - diferente dos anteriores, nos quais as quatro categorias citadas somavam por volta de metade do número de ocorrência de "Menções". Em Garritz e Chamizo, observa-se melhor distribuição das ocorrências entre essas quatro categorias, embora as mais recorrentes sejam a "Evolução linear" e a "Descrição" - que podem não ser as mais adequadas para desenvolver uma visão da complexidade da construção da ciência.

No que se refere à subdivisão "Responsável" pela evolução da ciência, na maioria das vezes as ideias ou descobertas foram atribuídas a um cientista trabalhando individualmente; porém, o número de menções à "Comunidade científica" também é significativo.

Considerando os assuntos dos capítulos onde há ocorrências em história da ciência, observa-se que o maior número delas aparece no capítulo sobre "Os Componentes dos Átomos" - o que coincide com o que foi observado nos dois outros livros analisados. $\mathrm{O}$ menor número de ocorrências encontra-se no capítulo intitulado "Reações de Oxirredução", novamente coincidindo com a observação dos demais livros. Observando as categorias em que o conteúdo histórico é mais aprofundado ("Descrição", "Períodos discretos", "Evolução linear" e "Evolução real"), nota-se que elas aparecem em menor número no primeiro capítulo do livro, "A Química e Nosso Mundo", enquanto que o maior número delas se encontra no capítulo referente à teoria atômica.

Pode-se destacar, também, que nas seções introdutórias de cada capítulo, Garritz e Chamizo inserem textos de uma ou duas páginas, enfocando a trajetória profissional de algum cientista latinoamericano que tenha destaque internacional, buscando aproximar os estudantes da ciência que é feita nos países da região. Por exemplo, um dos textos enfoca Mário Molina, destacando implicações científicas e econômicas de seu trabalho em química ambiental. O texto destaca a importância desse químico latinoamericano, com cuja origem os estudantes podem se identificar, ajudando a romper com o estereótipo do cientista "genial", europeu ou estadunidense, afastado no tempo e no espaço. Nos textos biográficos, Garritz e Chamizo destacam características como criatividade, interdisciplinaridade e versatilidade dos diversos cientistas enfocados.

\section{Dimensão 2 - Materiais utilizados para apresentar a informação histórica}

Nesta dimensão, foram analisados os diferentes recursos a que os autores recorreram para inserir aspectos da história da ciência em seus textos. Os resultados obtidos são apresentados na Tabela 3.

Tabela 3. Materiais utilizados para apresentar a informação histórica

\begin{tabular}{lccc}
\hline Categorias & $\begin{array}{c}\text { Kotz e } \\
\text { Treichel }\end{array}$ & $\begin{array}{c}\text { Atkins e } \\
\text { Jones }\end{array}$ & $\begin{array}{c}\text { Garritz e } \\
\text { Chamizo }\end{array}$ \\
\hline $\begin{array}{l}\text { Materiais utilizados para apresentar a } \\
\text { informação histórica }\end{array}$ & 2 & 8 & 28 \\
\hline Imagens de cientistas & 1 & 4 & 4 \\
Imagens de equipamentos, máquinas, etc. & 2 & 1 & 16 \\
Textos originais (fontes primárias) & 28
\end{tabular}

Fontes secundárias

Textos de historiadores da ciência

Modelos, representações, etc.

Ilustrações de equipamentos, experimentos, etc.

Textos pelo autor 6 2

Experimentos históricos

Outros

Observa-se, tanto em Kotz e Treichel, como em Atkins e Jones, a pequena utilização de materiais para a apresentação de informações históricas, o que confirma a opção desses autores pela superficialidade das informações apresentadas. Os poucos materiais que aparecem se concentram nas categorias de imagens de cientistas e de equipamentos, no caso de Atkins e Jones; ou de textos produzidos pelos próprios autores, no caso de Kotz e Treichel. Os textos originais, escritos por cientistas do passado (fontes primárias) somam apenas 3 ocorrências, computando-se conjuntamente os dois livros. Destaca-se também a total ausência de outras fontes secundárias que não a produção dos próprios autores dos livros. Em outras palavras, não há citação de trabalhos produzidos por historiadores da ciência - o que se apresenta como característica dos três livros analisados. Dentre os materiais utilizados por Kotz e Treichel, vemos que todas as imagens se concentram no capítulo dedicado a "Moléculas, íons e seus compostos". Os textos escritos pelo autor aparecem nos capítulos sobre "Átomos e Elementos" e "Estrutura Atômica" - que, conforme já apontamos, abrangem os assuntos nos quais mais se utiliza a abordagem histórica. Para todos os demais assuntos, portanto, nota-se ausência da utilização de materiais para apresentar o conteúdo histórico. Perfil semelhante se observa no livro de Atkins e Jones, no qual os assuntos privilegiados com a inserção de materiais históricos são aqueles relacionados ao desenvolvimento da teoria atômica, intitulados "Elementos e Átomos" e "Átomos: o Mundo Quântico" - embora haja ocorrências esparsas (uma ou duas) nos capítulos "Fundamentos - Introdução", "Mols e Massas Molares" e nos dois capítulos dedicados à Termodinâmica.

Em contraste, analisando a inserção de materiais para apresentar a história da ciência em Garritz e Chamizo, observou-se maior variedade de recursos neste livro, que inclui outros tipos de fontes secundárias além de textos. Nessa categoria, estão incluídos materiais produzidos pelos autores do livro didático ou por terceiros, tais como modelos, representações, ilustrações de equipamentos, esquemas de experimentos, etc., que têm a função de esclarecer as ideias do passado, mas que foram produzidos na atualidade. Observa-se também que os materiais utilizados por Garritz e Chamizo, em comparação 
com os dois outros livros, são não apenas mais variados, mas também mais abundantes e bem distribuídos ao longo do livro. Entre os nove capítulos da obra, todos apresentam materiais históricos, sendo o mínimo (6 ocorrências) observado no capítulo sobre "Ácidos e Bases", e o maior número de ocorrências (34) encontra-se no capítulo sobre "Os Componentes dos Átomos". A categoria mais frequente é a de "Textos pelo autor", a qual revela aprofundamento do conteúdo histórico inserido. Também chama a atenção o uso de citações literais de textos de cientistas ("Fontes primárias"), o que é significativo do ponto de vista da nova historiografia da ciência.

\section{Dimensão 3 - Contextos aos quais a informação histórica é relacionada}

Algumas ocorrências relativas à história da ciência aparecem, nos textos, relacionadas a contextos mais amplos, conforme se procura mostrar na Tabela 4.

Tabela 4. Contexto da informação histórica

\begin{tabular}{lccc}
\hline Categorias & $\begin{array}{c}\text { Kotz e } \\
\text { Treichel }\end{array}$ & $\begin{array}{c}\text { Atkins e } \\
\text { Jones }\end{array}$ & $\begin{array}{c}\text { Garritz e } \\
\text { Chamizo }\end{array}$ \\
\hline Contextualização & & & \\
\hline Total de ocorrências contextualizadas & 7 & 13 & 43 \\
\hline Contextos associados a essas ocorrências & & & \\
\hline Científico & 5 & 6 & 33 \\
Tecnológico & 2 & 9 & 22 \\
Social & 1 & 2 & 22 \\
Político & 2 & & 13 \\
Religioso & & & 1 \\
\hline
\end{tabular}

Em Kotz e Treichel, observa-se que o contexto mais trabalhado é o científico. Isso significa que a informação histórica acaba sendo relacionada apenas a outras ideias dentro da própria ciência. Em seguida, com igual número de ocorrências entre si, se seguem os contextos tecnológico e político. Essa esfera de análise possibilita também que se reflita acerca do aprofundamento dado à informação histórica. A contextualização, além de pressupor maior reflexão sobre o conteúdo histórico, é uma característica que se dá preferivelmente em ocorrências que foram classificadas como tendo maior aprofundamento, como descrição, evolução real ou linear, etc. As contextualizações se concentram no capítulo 11 (Compostos de carbono) - que, tomando-se como referência, é um daqueles em que a abordagem histórica é um pouco menos escassa. Observa-se, por outro lado, que nos capítulos onde se concentra o maior número de ocorrências (sobre "Átomos e Elementos" e "Estrutura Atômica"), apenas duas delas são contextualizadas. Aparentemente, a abordagem seguida na apresentação desses assuntos se fecha sobre si mesma, havendo poucas indicações de como esses assuntos se relacionam a outros temas da ciência, ou qual sua interação com a sociedade. Vale esclarecer que, embora haja um total de 10 contextos aos quais ocorrências de história da ciência foram associados, o número absoluto de ocorrências é de apenas 7. Isto acontece porque uma mesma ocorrência pode ser associada a mais de um contexto.

Em Atkins e Jones, observa-se a concentração das ocorrências nos contextos científico e tecnológico, e a ausência de contextualização política ou religiosa. A maioria das ocorrências se dá no capítulo referente a "Átomos: o mundo quântico", seguido pelos "Fundamentos" no início do livro. Observa-se contextualização para 13 ocorrências, que resultam em 17 contextos associados a elas no total.

Em Garritz e Chamizo, também para a dimensão de análise refe- rente ao "Contexto", observa-se maior número de ocorrências do que nos outros dois livros. Essas ocorrências encontram-se distribuídas ao longo das categorias (embora o contexto religioso quase não seja contemplado) e dos capítulos, de modo que nenhum capítulo fica isento de alguma referência histórica contextualizada. Essa distribuição indicia também maior aprofundamento da abordagem histórica do que nos outros livros analisados. Foram identificadas 43 ocorrências distintas em que havia referência a um ou mais contextos - em termos relativos, número significativamente maior do que nos outros dois livros, se consideramos a relação entre esse número e o total de ocorrências mais aprofundadas.

\section{Dimensão 4 - Estatuto do conteúdo histórico}

A Tabela 5 permite observar qual o papel atribuído à informação histórica dentro do texto: se ela vem inserida no desenvolvimento didático dos conteúdos, ou se ela vem à parte, como curiosidade - em caixas separadas, por exemplo.

Tabela 5. Estatuto da informação histórica

\begin{tabular}{lccc}
\hline Categorias & $\begin{array}{c}\text { Kotz e } \\
\text { Treichel }\end{array}$ & $\begin{array}{c}\text { Atkins e } \\
\text { Jones }\end{array}$ & $\begin{array}{c}\text { Garritz e } \\
\text { Chamizo }\end{array}$ \\
\hline Estatuto da informação histórica & & & \\
\hline Fundamental & 81 & 72 & 210 \\
Complementar & 7 & 15 & \\
\hline
\end{tabular}

Em Kotz e Treichel foi possível observar que, em 8 dos 14 capítulos, todo o conteúdo histórico foi inserido no texto, como fundamental para todos os alunos. Em apenas um capítulo o número de ocorrências classificadas como fundamentais (3) foi aproximadamente o mesmo daquelas classificadas como complementares (2): o capítulo sobre "Matéria e Medição".

Em Atkins e Jones, pode-se observar maior número de ocorrências de conteúdos históricos em material considerado complementar, em comparação com o livro de Kotz e Treichel. No livro de Atkins e Jones, esses conteúdos aparecem, na maioria das vezes, em caixas separadas do texto, e se distribuem pelos vários capítulos em que há ocorrências de caráter histórico.

Em Garritz e Chamizo, vê-se que todas as ocorrências foram inseridas no livro como sendo fundamentais, destinadas a todos os alunos, em dissonância com os livros anteriores onde algumas ocorrências aparecem como sendo complementares, não integrando a parte principal do texto. Claramente, Garritz e Chamizo adotam a abordagem histórica como um dos eixos na elaboração do seu livro didático.

\section{Dimensão 5 - Atividades de aprendizagem que abrangem a história da ciência}

Analisando as atividades de aprendizagem sugeridas para os alunos (como exercícios), Tabela 6 , envolvendo de alguma forma a história da ciência, encontramos apenas 2 delas no livro de Kotz e Treichel. Cada uma dessas atividades traz um único dado quantitativo histórico para ser trabalhado pelos alunos:

39. Há mais ou menos dois séculos, Benjamin Franklin mostrou que 1 tsp [colher de chá] de óleo cobriria cerca de 0,5 acre de água parada. Sabendo que $1,0 \times 10^{4} \mathrm{~m}^{2}=2,47$ acres e que há aproximadamente $5 \mathrm{~cm}^{3}$ em uma colher de chá, qual é a espessura da camada de óleo? Como essa espessura poderia ser relacionada ao tamanho das moléculas? (p. 33) ${ }^{9}$ 
Tabela 6. Atividades de aprendizagem que abrangem a história da ciência

\begin{tabular}{cccc}
\hline Categorias & Kotz e & Atkins e & Garritz e \\
Treichel & Jones & Chamizo
\end{tabular}

Estatuto da atividade

\begin{tabular}{llll}
\hline Compulsória & 1 & 4 & 4 \\
Livre & 1 & & 7 \\
\hline
\end{tabular}

Tipo de atividade

Guia de leitura

1

Pesquisa bibliográfica

7

Análise de informação histórica

Experimentos históricos

Outros

2

3

O balão utilizado por Jacques Charles em seu voo histórico em 1783 foi preenchido com aproximadamente $1300 \mathrm{~mol} \mathrm{de}$ $\mathrm{H}_{2}$. Se a temperatura do gás fosse $23{ }^{\circ} \mathrm{C}$, e sua pressão, 750 $\mathrm{mmHg}$, qual seria o volume do balão? (p. 443)

Observa-se que a relação com a história da ciência é extremamente tênue em ambos os casos: a origem dos dados é irrelevante para os objetivos das atividades.

Encontramos, em Atkins e Jones, 4 ocorrências desse tipo de atividades de ensino em todo o livro, sempre com as mesmas características: atividades destinadas a todos os alunos, envolvendo a análise de informações históricas, e inseridas em capítulos que tratam da teoria atômica. Embora sejam poucas, essas atividades são um pouco mais elaboradas que as propostas por Kotz e Treichel, conforme exemplifica o seguinte exercício:

Na época que J. J. Thomson conduziu seu experimento com os raios catódicos, a natureza do elétron era duvidosa. Alguns o consideravam uma forma de radiação; outros acreditavam que era uma partícula. Algumas das observações feitas sobre os raios catódicos foram usadas como suporte para uma ou outra visão. Mostre como cada uma das seguintes propriedades dos raios catódicos suporta o modelo de radiação ou o modelo de partícula do elétron. (a) Eles passam através de folhas metálicas. (b) Viajam a velocidades mais baixas do que a da luz. (c) Se um objeto for colocado em seu caminho, eles provocam uma sombra. (d) Seu caminho é defletido quando passam através de placas eletricamente carregadas. (p. 46) ${ }^{10}$

Observa-se, aqui, a presença da ideia de que há debates em torno da interpretação dos experimentos, ou seja, esta ideia se opõe a um empirismo ingênuo de acordo com o qual os experimentos fornecem dados "isentos" sobre a Natureza. Além disso, também se opõe à concepção de que se estabelece consenso imediato no momento em que se anuncia uma nova "descoberta". Entretanto, é discutível o impacto dessa ideia sobre os alunos, considerando a escassez de atividades desse tipo no livro como um todo.

Também nesta dimensão de análise o livro de Garritz e Chamizo mostrou maior número de ocorrências do que nos dois outros livros analisados. Garritz e Chamizo propõem 11 atividades, de três diferentes tipos. Os outros livros apresentavam menor número de atividades, e de somente um tipo. Observa-se que a maioria das atividades de aprendizagem em Garritz e Chamizo estão indicadas como complementares, enquanto no livro de Atkins e Jones todas as atividades eram colocadas como obrigatórias.

\section{Dimensão 6 - Consistência interna do livro (no que se refere à} informação histórica)

Analisando os livros capítulo a capítulo, pode-se obter uma visão panorâmica de quais assuntos são mais, e quais são menos, favorecidos quando os autores fazem referência à história da ciência. Observa-se que nos livros de Kotz e Treichel e de Atkins e Jones a distribuição das ocorrências em história da ciência é bastante desigual, estando concentrada em alguns capítulos. Em Garritz e Chamizo, a distribuição é mais homogênea.

Observa-se em Kotz e Treichel um grande número de ocorrências no capítulo referente a átomos e ao desenvolvimento da teoria atômica. Nesse capítulo, não apenas se tem um grande número de ocorrências, como também um maior número de ocorrências com mais aprofundamento. Seguindo o mesmo critério, o capítulo sobre estrutura atômica é o segundo em número de ocorrências com maior aprofundamento, e de ocorrências em geral. Pode-se observar também que a categoria "evolução real" (que sugere uma concepção historiográfica mais próxima das tendências atuais da área) se concentra praticamente nos capítulos relacionados à teoria atômica, assunto que parece ser privilegiado para uma abordagem do ponto de vista histórico. Em seguida, aparecem os capítulos sobre compostos de carbono e sobre o estudo dos gases como outros assuntos mais trabalhados neste livro sob a perspectiva histórica. Por outro lado, considerando os assuntos menos trabalhados sob essa perspectiva, vemos total ausência de abordagem histórica no capitulo referente a reações químicas em solução aquosa, bem como uma abordagem pequena e superficial nos capítulos sobre equações químicas e ligações químicas.

Na seção introdutória do livro de Atkins e Jones, vemos que o tópico com maior número de ocorrências em história da ciência foi aquele intitulado "Elementos e Átomos"; e entre os capítulos de 1 a 8 o tópico com mais ocorrências históricas foi "Átomos: o mundo quântico" - coincidindo, portanto, com os assuntos mais privilegiados com a abordagem histórica no livro de Kotz e Treichel. Por outro lado, o assunto com menor número de ocorrências de caráter histórico em Atkins e Jones foi "termodinâmica: a segunda e a terceira lei". Na seção introdutória, entre os itens que não apresentaram ocorrências históricas observa-se a presença do que trata de reações em soluções aquosas, assunto que também não foi contemplado com nenhuma ocorrência de caráter histórico por Kotz e Treichel. Para o assunto "equações químicas", não houve ocorrência em Atkins e Jones, e apenas uma em Kotz e Treichel. Um aspecto que nos chamou a atenção foi a coincidência na escolha da abordagem histórica para determinados assuntos em ambos os livros, e que pode ser observada também em outros livros didáticos de química geral. As razões para que determinados tópicos sejam escolhidos para receber um enfoque histórico, e outros não, se apresentam como perspectiva para futuras investigações.

Um dos pontos que diferenciam a abordagem de Garritz e Chamizo em relação a outros livros de química geral é a presença de menções à história da ciência em todos os capítulos, em vez de apenas concentrada em poucos tópicos. Essas ocorrências integram o próprio desenvolvimento dos assuntos, mais do que em "caixas" isoladas do texto principal - como em livros que as sugerem como leituras complementares. Observa-se também a distribuição mais uniforme pelos capítulos de textos mais longos, revelando menor superficialidade na abordagem. Assim, a abordagem de Garritz e Chamizo se aproxima mais daquela que Matthews denominou "abordagem integrada", ${ }^{5}$ na qual a história da ciência se apresenta como um dos fios condutores do conteúdo científico trabalhado no livro.

\section{Dimensão 7 - Bibliografia em história da ciência}

É de se destacar que o livro de Garritz e Chamizo apresentou uma 
dimensão de análise que está ausente dos outros dois livros, referente à bibliografia recomendada (Tabela 7).

Tabela 7. Bibliografia recomendada

\begin{tabular}{lccc}
\hline Categorias & Kotz e & Atkins e & Garritz e \\
& Treichel & Jones & Chamizo \\
\hline
\end{tabular}

Livros de história da ciência 12

Livros de ciência que abordam o desen14 volvimento da ciência

Livros de áreas afins 1

Em virtude de haver repetições de indicações bibliográficas nos diferentes capítulos, optou-se aqui por apresentar, na Tabela 7, os dados colhidos no livro como um todo, ou seja, livros que são referenciados em mais de um capítulo foram computados uma única vez. Os livros eram recomendados no final das seções, como leitura complementar.

\section{Dimensão 8 - Exatidão e precisão da informação histórica}

Procurando fazer uma investigação qualitativa a respeito da concepção historiográfica dos autores do livro, fizemos uma releitura de ocorrências onde os conteúdos de história fossem mais aprofundados. Um dos critérios de avaliação que ajuda a identificar o aprofundamento destes conteúdos é o critério "texto pelo autor", na Tabela 3. A categoria "Textos pelo autor" identifica trechos onde o autor trabalhou os conteúdos de história da ciência de forma mais aprofundada; sendo assim, este critério é bastante satisfatório para podermos visualizar o posicionamento dos autores quanto à evolução da ciência.

No livro de Kotz e Treichel, existem ao todo 6 ocorrências de "textos pelo autor". Observou-se, nesses textos, uma tendência a apresentar a evolução da ciência de maneira linear e não problemática, selecionando apenas as ideias que ainda são aceitas pela ciência atual e excluindo as controvérsias. Assim, a ênfase recai sobre os "produtos" da ciência e não sobre o processo que leva à construção do conhecimento científico. A narrativa não necessariamente reflete a sequência histórica dos acontecimentos e, em geral, reforça um modelo empírico-indutivista para a ciência. Segue-se um exemplo:

Um objetivo dos cientistas do final do século XIX era explicar porque os átomos gasosos emitem luz de somente determinadas frequências e encontrar uma relação matemática entre as frequências observadas... Os primeiros passos nesse sentido foram dados por Johann Balmer (1825-1898) e, mais tarde, por Johannes Rydberg (1854-1919). Eles desenvolveram uma equação - chamada agora de equação de Rydberg... O físico dinamarquês Niels Bohr (1885-1962) forneceu a primeira conexão entre os espectros dos átomos excitados e as ideias quânticas de Planck e Einstein. Do trabalho de Rutherford, sabia-se que os elétrons são arranjados no espaço exterior ao núcleo do átomo. Para Bohr, o modelo mais simples de um átomo de hidrogênio era aquele em que o elétron se move em uma órbita circular ao redor do núcleo... (p. 234) ${ }^{9}$

O processo da ciência é apresentado como uma sequência não problemática, no qual uma ideia conduz à outra, de maneira linear: estão ausentes as divergências, as interpretações alternativas, as controvérsias. Do processo histórico são pinçadas as ideias que, de alguma forma, podem ser consideradas partes dos conceitos atuais, idealizando a maneira como esses conceitos foram construídos.

Kotz e Treichel utilizam o relato referente à tabela periódica para idealizar o funcionamento da ciência. Vejamos alguns fragmentos:
A característica mais importante da tabela de Mendeleev - e marca de sua genialidade e de sua audácia - foi que ele deixava um espaço vazio em uma coluna quando um elemento não era ainda conhecido, mas deveria existir e ter as propriedades similares às do elemento que se situaria acima dele na tabela. Ele deduziu que esses espaços seriam preenchidos por elementos ainda não descobertos. (p. 54)

Neste trecho, Kotz e Treichel ressaltam a "genialidade" e a "audácia" de Mendeleev, o que pode reforçar a ideia de que a ciência é feita por "gênios", dificultando a identificação do estudante com a atividade científica. Tampouco há referência, no texto de onde foi extraído esse fragmento, aos anos de trabalho que Mendeleev dedicou aos estudos que o levaram à proposição da classificação periódica dos elementos.

Um problema com a tabela de Mendeleev era que os elementos estavam listados em ordem crescente de massa. Observando-se uma tabela moderna vê-se que, com base nisso, o $\mathrm{Ni}$ e o Co, entre outros, deveriam ser invertidos. Mendeleev supôs que as massas atômicas conhecidas naquela época eram inexatas, o que não era má suposição, baseando-se nos métodos analíticos então em uso. Na verdade, a sua ordem estava correta, e o que estava errada era a sua suposição de que as propriedades de um elemento eram uma função da sua massa. Em 1913, H. G. J. Moseley (1887-1915) ...corrigiu a suposição de Mendeleev. (p. 54) ${ }^{9}$

Observa-se que Kotz e Treichel adotam uma perspectiva presentista, apontando "problemas" e "correções" que somente são entendidos como tal do ponto de vista do conhecimento atual, e não do conhecimento existente na época retratada. Dessa forma, deixam passar a oportunidade de mostrar que as evidências experimentais não fornecem critérios absolutos: entre o que considerava uma boa hipótese (sua lei periódica) e os dados experimentais (as massas atômicas do Ni e do Co), Mendeleev preferiu acreditar que a hipótese estava correta e os experimentos, errados.

\section{A Tabela Periódica e o Método Científico \\ O desenvolvimento da Tabela Periódica ilustra o modo pelo qual a química se desenvolveu: as observações experimentais conduziam a correlações empíricas das propriedades e daí à predição dos resultados a serem testados por experiências adicionais. Uma vez que as predições fossem testadas, uma teoria poderia então ser desenvolvida. (p. 54) ${ }^{9}$}

Aqui, os autores idealizaram um processo de construção da ciência que ocorreria "fora do tempo", pois não há qualquer referência às circunstâncias históricas que podem fazer com que o processo ocorra seguindo esse caminho ou não. No caso em questão, entre o teste das previsões de Mendeleev e o desenvolvimento de uma teoria que explica, ainda que não de maneira completa, a periodicidade das propriedades químicas, algumas décadas se passaram. Além disso, essa teoria existe em um panorama conceitual muito distinto daquele no qual Mendeleev trabalhava, incluindo novos conceitos de estrutura atômica, de elemento químico e de ligação química, por exemplo.

A abordagem de Atkins e Jones não é muito diferente. Selecionamos a seguir três fragmentos, que servem para discutir alguns aspectos que consideramos relevantes a respeito da abordagem desses autores para a história da ciência. $\mathrm{O}$ primeiro trecho se refere aos modelos atômicos:

[O]s cientistas, no começo do século XX, sabiam que cada átomo devia conter um número suficiente de cargas positivas 
para cancelar a carga negativa. Mas, onde estava a carga positiva? Thomson sugeriu um modelo de átomo como uma bolha positivamente carregada, de material gelatinoso, com elétrons suspensos nela, como passas em um pudim. Entretanto, este modelo foi derrubado em 1908 por um experimento simples. Ernest Rutherford estava treinando alguns de seus estudantes para usarem peças novas do equipamento... Ele pediu a dois estudantes, Hans Geiger e Ernest Marsden, para atirarem partículas contra um pedaço de folha de platina de somente uns poucos átomos de espessura. Se os átomos fossem de fato como bolhas de geleia carregadas positivamente, então as partículas deveriam passar facilmente através da folha, com alguma ligeira deflexão ocasional de seus caminhos. O que Geiger e Marsden observaram perturbou a todos a sua volta... A explicação tinha que ser a que os átomos não têm bolhas de geleia positivamente carregadas com os elétrons suspensos como passas em um pudim. Ao invés disso, os resultados sugerem um modelo de átomo no qual há uma densa carga positiva central circundada por um grande volume de espaço vazio. (p. 47-48) ${ }^{10}$

Nesse fragmento, podemos observar a presença do mito do "experimento crucial": o "experimento simples" de Geiger e Marsden teria sido capaz de "derrubar" o modelo atômico de Thomson. Ao exporem o episódio histórico dessa maneira, Atkins e Jones reforçam duas visões equivocadas. Uma delas, a de que os experimentos fornecem um olhar isento sobre a Natureza e, assim, bastaria uma evidência contrária para que uma teoria fosse abandonada. Sabe-se, porém, que a prática científica ocorre de maneira bastante diversa e, em geral, as teorias somente são abandonadas quando podem ser substituídas por outras consideradas mais satisfatórias. Além disso, é preciso lembrar que a própria observação é orientada por uma série de pré-concepções, podendo ser "ajustadas" a diferentes panoramas teóricos. (Dois textos úteis para discutir esse ponto em contextos didáticos são: Collins e Pinch, "Os germes da discórdia: Louis Pasteur e as origens da vida"; e Martins, "Pasteur e a geração espontânea: uma história equivocada"). ${ }^{13}$ Outra visão equivocada sugerida pelo texto é a de que só havia o modelo de Thomson nessa época e que ele teve que ser substituído pelo modelo de Rutherford. De fato, porém, havia diversos modelos atômicos em discussão no período (incluindo modelos "nucleares" anteriores ao de Rutherford) e questões sobre a localização das cargas elétricas e a estabilidade do átomo não permitiam que fosse possível chegar a um consenso imediato sobre qualquer dos modelos. ${ }^{14}$ Como curiosidade, podemos acrescentar que a analogia entre o modelo de Thomson e um "pudim de passas", mencionada por Atkins e Jones e muitos outros livros didáticos, é totalmente inadequada, pois o modelo em questão não descrevia elétrons estáticos distribuídos aleatoriamente, mas movendo-se em anéis concêntricos dentro da esfera positiva. ${ }^{14}$

$\mathrm{O}$ trecho a seguir faz parte de um texto referente à elaboração da tabela periódica:

Frequentemente existem descobertas simultâneas em ciência, porque as descobertas tendem a ser feitas quando dados suficientes e de boa qualidade foram coletados. (p. 162) ${ }^{10}$

A referência à coleta de "dados suficientes e de boa qualidade" pode sugerir aos alunos a ideia de que a ciência vai sendo construída pela acumulação de dados, de maneira linear.

O terceiro exemplo refere-se aos estudos de Boyle com o ar:

Boyle pegou um tubo longo de vidro moldado em forma de J, com o lado menor lacrado. Ele então verteu mercúrio no tubo, prendendo ar no lado menor do J. Quanto mais mercúrio adicionava, mais o gás era comprimido. Boyle concluiu que o volume de uma quantidade fixa de gás diminui quando a pressão sobre ele aumenta... Porém, os cientistas procuram frequentemente colocar os dados experimentais em gráficos... Boyle encontrou que os dados dele deram uma linha reta quando os pôs em um gráfico da pressão contra 1/volume. (p. 267) $)^{10}$

Neste trecho, observa-se que o esforço de Atkins e Jones em conformar a história a um certo modelo ideal para o desenvolvimento da ciência os conduz a um relato anacrônico. Embora, de fato, a ciência atual esteja repleta de representações gráficas como forma de sistematização de dados e teorias, essa característica estava longe de estar consolidada no século XVII, quando a ciência moderna estava apenas nascendo. $\mathrm{Na}$ obra em que descreveu seus estudos sobre o comportamento do ar, Boyle apresentou os resultados que obteve na forma de tabelas, e não de gráficos. ${ }^{15}$

No que se refere ao livro de Garritz e Chamizo, as ocorrências classificadas como "Textos pelo autor" se constituem em material especialmente apropriado para análise qualitativa do conteúdo de história da ciência, pois nessas ocorrências o conteúdo é trabalhado de forma mais aprofundada. Tal seleção serve também como referência para comparação entre os diferentes livros analisados, em especial no que tange às alternativas possíveis para abordagens históricas no ensino de química, visto que Garritz e Chamizo explicitamente se comprometem com essa proposta.

Existem algumas semelhanças entre os três livros analisados, no sentido de que suas abordagens em geral estão mais próximas da antiga historiografia da ciência do que das tendências atuais dessa área. Também se observa coincidência quanto aos assuntos em que aparece o maior número de ocorrências em história da ciência: aqueles que se referem à teoria atômica. Em Garritz e Chamizo, porém, a abordagem histórica se estende para um número muito maior de conteúdos. Garritz e Chamizo utilizam a abordagem histórica também para contextualizar aplicações do conhecimento químico - por exemplo, ao enfocar a questão do desenvolvimento de drogas hoje ilícitas e antes comercializadas (como a cocaína, considerada em certo momento histórico como medicamento) e seus impactos negativos sobre a sociedade. A seguinte passagem é representativa:

Os fungos alucinógenos que crescem no sul do México foram empregados em cerimônias religiosas durante os últimos 2500 anos. O químico suíço A. Hoffmann, que sintetizou o LSD, descobriu em 1956 seu princípio ativo, a psilocina, de estrutura muito parecida com o neurotransmissor serotonina. O LSD (dietilamida do ácido lisérgico) é uma droga extremamente poderosa. Para surtir efeito bastam de 10 a $100 \mu \mathrm{g}$, ao passo que um comprimido de aspirina tem $300000 \mu \mathrm{g}$ de ácido acetilsalicílico. (p. 596) ${ }^{11}$

Conforme foi mencionado na análise da Dimensão 1, as seções introdutórias de cada capítulo apresentam aspectos biográficos de cientistas latinoamericanos contemporâneos e que tenham alcançado destaque internacional. Como já mencionado, isso pode reforçar a identificação dos alunos com os cientistas - inclusive mulheres, que também são apresentadas como exemplos de sucesso em suas carreiras. Este é o caso, por exemplo, da química brasileira Eloísa Mano, sobre quem Garritz e Chamizo escrevem:

A produção científica de Eloísa Mano abrange ainda a orientação de 38 teses de mestrado e 9 de doutorado. É autora de 10 livros e de três capítulos de livros, tem 188 trabalhos 
publicados em periódicos nacionais e internacionais... Apresentou centenas de conferências no país e no exterior e detém o registro de 6 patentes.

Foi contemplada com o Prêmio Cidade do Rio de Janeiro de Ciência e Tecnologia (2000)... Recebeu a Grã-Cruz da Ordem Nacional do Mérito Científico, área de Química (2000). Foi distinguida com o prêmio 1997 International Award of the Society of Polymer Science, Japão, e com o prêmio da Engineering Properties and Structure Division/ Central Florida Section of the Society of Plastics Engineers (SPE), EUA (2000). Foi também contemplada com a Medalha Simão Mathias em reconhecimento às contribuições para o desenvolvimento da química no país. (p. 306) ${ }^{11}$

Os objetivos pretendidos pelos autores com esses textos são muito importantes. Pode-se especular, apenas, se, ao verem listados tantos méritos e prêmios dos cientistas, os alunos não se sintam diante de "gênios", com os quais acabem não se identificando, ainda que também latinoamericanos. Para verificar isso, porém, seria necessária uma investigação que foge ao escopo do presente trabalho.

Garritz e Chamizo também utilizam diferentes instrumentos para apresentar aspectos históricos: diagramas, tabelas, representações de experimentos, etc. Alguns desses instrumentos são inovadores, embora por vezes transmitam uma visão linear e acumulativa da ciência - mais próxima, portanto, de uma abordagem historiográfica hoje superada (Figura 1).

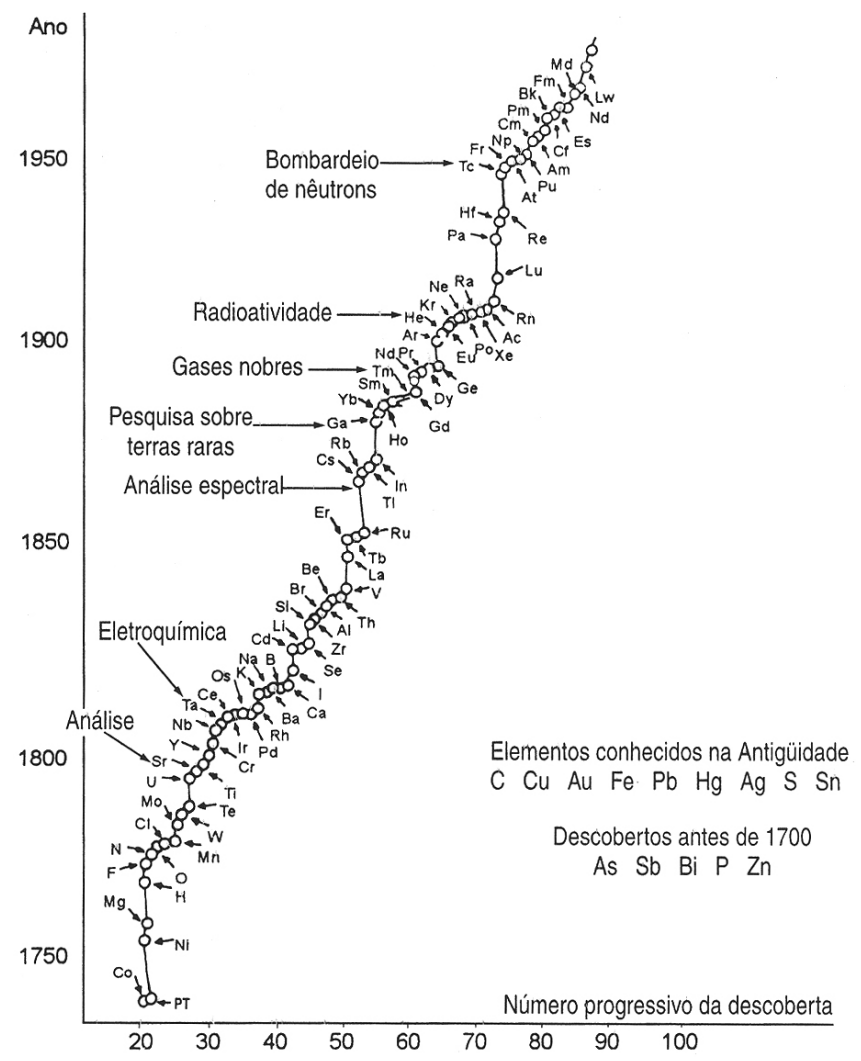

Figura 1. Ilustração usada por Garritz e Chamizo para mostrar a cronologia da "descoberta dos elementos"

A Figura 1 traz um exemplo disso, retirado do livro de Garritz e Chamizo: um diagrama que ilustra a "descoberta dos elementos" químicos ao longo do tempo. A ilustração é criativa na sua apresentação, mostrando de maneira compacta a relação entre o desenvolvimento de técnicas de análise e síntese e o seu potencial para a produção de novas substâncias simples. Entretanto, sugere um conhecimento científico linear e acumulativo, descrito sob a perspectiva presentista. Não há espaço para a discussão de que o próprio conceito de elemento químico foi se transformando com o tempo, ou que listar "elementos conhecidos na Antiguidade" somente faz sentido à luz de critérios que não existiam na Antiguidade.

Os autores demonstram preocupação quanto às fontes em história da ciência, aspecto praticamente ausente de outros livros analisados. Em Garritz e Chamizo, encontram-se várias citações literais de textos de cientistas, o que é significativo do ponto de vista da nova historiografia da ciência. Além disso, observou-se que os autores se preocupam em fornecer referências bibliográficas referentes à história da ciência e áreas afins, como sugestões para leituras complementares, o que não ocorreu nos outros dois livros analisados.

\section{Categorias complementares}

As categorias complementares que propusemos encontram-se tabuladas na sequência. Foram consideradas para análise apenas as ocorrências classificadas anteriormente como "Descrição", "Períodos discretos", "Evolução linear" e "Evolução real".

Os resultados obtidos para as categorias complementares foram reunidos na Tabela 8 .

Tabela 8. Categorias complementares

\begin{tabular}{lccc}
\hline Categorias & $\begin{array}{c}\text { Kotz e } \\
\text { Treichel }\end{array}$ & $\begin{array}{c}\text { Atkins e } \\
\text { Jones }\end{array}$ & $\begin{array}{c}\text { Garritz e } \\
\text { Chamizo }\end{array}$ \\
\hline Teoria versus prática & & & \\
\hline apenas teoria & 25 & 26 & 77 \\
prática associada à teoria & 4 & 5 & 30 \\
\hline Região & 28 & 29 & 90 \\
\hline Ocidente (Europa, EUA) & & & 4 \\
Extremo Oriente & 1 & 1 & 3 \\
$\begin{array}{l}\text { Oriente Próximo (mesopotâmicos, árabes, } \\
\text { persas,...) }\end{array}$ & & & \\
América Latina & & & 26 \\
África & & & \\
\hline Períodos & 1 & 3 & 11 \\
\hline Antiguidade/Medievo & & & 3 \\
sécs. XV/XVI & & 4 & 6 \\
séc. XVII & & 1 & 14 \\
séc. XVIII & 4 & 14 & 50 \\
séc. XIX & 19 & 22 & 65 \\
séc. XX & 17 & 2 & \\
séc. XXI & & & \\
\hline & & & \\
\hline
\end{tabular}

Observa-se, tanto em Kotz e Treichel quanto em Atkins e Jones, existir semelhança no que tange ao predomínio de ocorrências focadas apenas em aspectos teóricos e número pequeno de ocorrências em que estes se encontram associados à prática. Em Garritz e Chamizo, embora também predomine a categoria em que o evento histórico está associado somente à teoria, em termos relativos a associação entre teoria e prática aparece de maneira bem mais pronunciada neste livro do que nos demais (30 de 107 ocorrências).

No que tange à localização geográfica, é preciso ressalvar que as categorias geográficas não são excludentes: uma mesma ocorrência pode se referir, por exemplo, ao Oriente Próximo e ao Ocidente. Observa-se em Kotz e Treichel e Atkins e Jones o absoluto predomí- 
nio da perspectiva centrada no Ocidente, enquanto essa prevalência é relativamente menor em Garritz e Chamizo. Nesta dimensão de análise surge um dado interessante a respeito deste último livro: a grande quantidade de ocorrências relacionadas à América Latina. Isso manifesta uma das propostas do livro, que é aproximar a ciência dos alunos latinoamericanos através da história da ciência na região.

Também foi investigado o período histórico a que se referem às ocorrências em história da ciência em cada livro. Como era de se esperar, predominam as ocorrências referentes aos séculos XIX e XX - período em que a química consolidou seu ingresso na modernidade. Em Kotz e Treichel, o número de ocorrências para o século XX supera as do século XIX, enquanto que no livro de Atkins e Jones se observa haver mais ocorrências distribuídas por outros períodos (século XVII, Antiguidade), em comparação com Kotz e Treichel. Em Garritz e Chamizo, chama a atenção a existência de mais ocorrências relativas à Antiguidade e ao século XVIII do que nos dois livros anteriores.

\section{CONSIDERAÇÕES FINAIS}

Os livros analisados representam diferentes tendências da inclusão da história da ciência no ensino de química. Kotz e Treichel e Atkins e Jones recorrem à história mais como curiosidade e ilustração. Garritz e Chamizo adotam a abordagem histórica como um dos eixos na organização do livro, discutindo episódios e ideias com maior profundidade. Portanto, a abordagem de Garritz e Chamizo é mais condizente com os ideais preconizados por educadores que recomendam a história da ciência como estratégia de ensino. A forma como este livro apresenta os conteúdos de história da ciência abre campo para outras reflexões. O livro de química geral de Garritz e Chamizo representa uma interessante proposta, ainda que alguns reparos de natureza historiográfica possam ser feitos. Os autores demonstram que a abordagem histórica não precisa se restringir a dados biográficos de cientistas e simples menções a ideias e descobertas. Relatos mais aprofundados podem auxiliar o estudante em diferentes aspectos de seu aprendizado: na construção de conceitos de química; na compreensão da complexidade da atividade científica ao longo do tempo; bem como no entendimento do fazer científico na atualidade.

\section{AGRADECIMENTOS}

À FAPESP (Processo 2007/02542-4), pelo financiamento à pesquisa. À Pró-Reitoria de Graduação da USP, pela concessão de bolsa de Iniciação Científica (Programa Ensinar com Pesquisa).

\section{REFERÊNCIAS}

1. Campanario, J. M.; Enseñanza de las Ciencias 2001, 19, 351.

2. Kuhn, T. S.; A estrutura das revoluções científicas, $3^{\mathrm{a}}$ ed., Boeira, B. V.; Boeira, N., trads.; Perspectiva: São Paulo, 1990.

3. Kuhn, T. S.; A tensão essencial, Pacheco, R., trad.; Edições 70: Lisboa, 1989, p. $279-280$

4. Na edição brasileira de A estrutura das revoluções científicas, a palavra textbook foi traduzida como "manual". Optamos por nos referir a esse gênero literário como "livro didático".

5. Matthews, M. R.; Science teaching - the role of history and philosophy of science, Routledge: Nova York, 1994.

6. Porto, P. A. Em Ensino de Química em Foco; Santos, W. L. P.; Maldaner, O. A., orgs.; Editora Unijuí: Ijuí, 2010, p. 159-180.

7. Martins, R. A. Em Estudos de história e filosofia das ciências subsídios para aplicação no ensino; Silva, C. C., org.; Ed. Livraria da Física: São Paulo, 2006, Introdução.

8. Leite, L.; Science \& Education 2002, 11, 333.

9. Kotz, J. C.; Treichel, P.; Química e Reações Químicas, Bonapace, J. A. P.; Barcia, O. E., trads.; Livros Técnicos e Científicos: Rio de Janeiro, 2002.

10. Atkins, P. W.; Jones, L.; Princípios de Química, Caracelli, I. et alii; trads.; Bookman: Porto Alegre, 1999.

11. Garritz-Ruiz, A.; Chamizo, J. A.; Química, Pearson: São Paulo, 2000.

12. Alfonso-Goldfarb, A. M.; Ferraz, M. H. M.; Beltran, M. H. R. Em Escrevendo a história da ciência: tendências, propostas e discussões historiográficas; Alfonso-Goldfarb, A. M.; Beltran, M. H. R., orgs.; Educ/Fapesp: São Paulo, 2004, p. 49-73; Martins, R. A. Em ibid, p. 115-145; Debus, A. G.; Rev. Soc. Bras. de Hist. da Ciênc. 1991, 5, 3.

13. Collins, H.; Pinch, T.; O Golem - o que você deveria saber sobre ciência, Oliveira, L. C. B., trad.; Editora Unesp: São Paulo, 2003, cap. 4; Martins, L. A.-C. P.; Filosofia e História da Biologia 2009, 4, 65.

14. Lopes, C. V. M.; Tese de Doutorado, Pontifícia Universidade Católica de São Paulo, Brasil, 2009.

15. Porto, P. A.; Ciência Hoje 2010, 46, 75. 